BRTTISH MEDICAL JOURNAL VOLUME $288 \quad 3$ MARCH 1984 PRACTICE OBSERVED

\section{Continuing Education}

\section{It's come a long way}

RICHARD HOBBS

Continuing education in general practice as a formal programme
of activities has only existed since the 1950 s and, whatever the
inagequacies now, has come an astonishingly long way since inadequacies now, has come an astonishingly long way since
then. The academic and financial status of general practitioner Then. Perhaps at its lowest ebb then.
wn 1950 the BMA first supported the idea of a three year

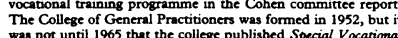
was not until 1965 that the college publisbed Special Vocational
Training for General Practice, which was submitted to the Royal
Commission on Medical Education and endorsed in 1968 . Commission on Medical Eduction and endorsed in 1988.
Posteraduate training for general practitioners became a lega
requirement in February 1981 for entry into practice. Gradual requirement in February 1981 for entry into practice. Gradual
end systematic change led to vocational training becoming
voluntarily enshrined in legistation. Certainly the impertus for

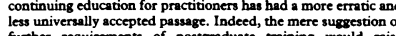

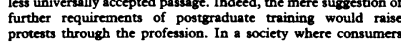
protests through the profession. In a society where consumer
are increasingly aware, however, and governments ever more concerned about value for money, the onus on the professsion to
diseeminate higher standards and better accountability should be encouraging a greater provision for and uptake of continuing Continuing education has existed through an organised
progeramme of postgraduate activities since the latec 1960 . The Nuffield conference of 1961 led to the proliferation of post-
graduate medical centres in Britain.' It is interesting that the relative meris of a proegramme for posteranduate general prac
titioners was not thought to be sufficiendly important to include titioners was not hought to be sufficiently important to include
in the programme of such a major syposium. When format
postgraduate sessions on general practice begen to appear at

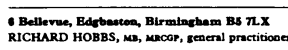
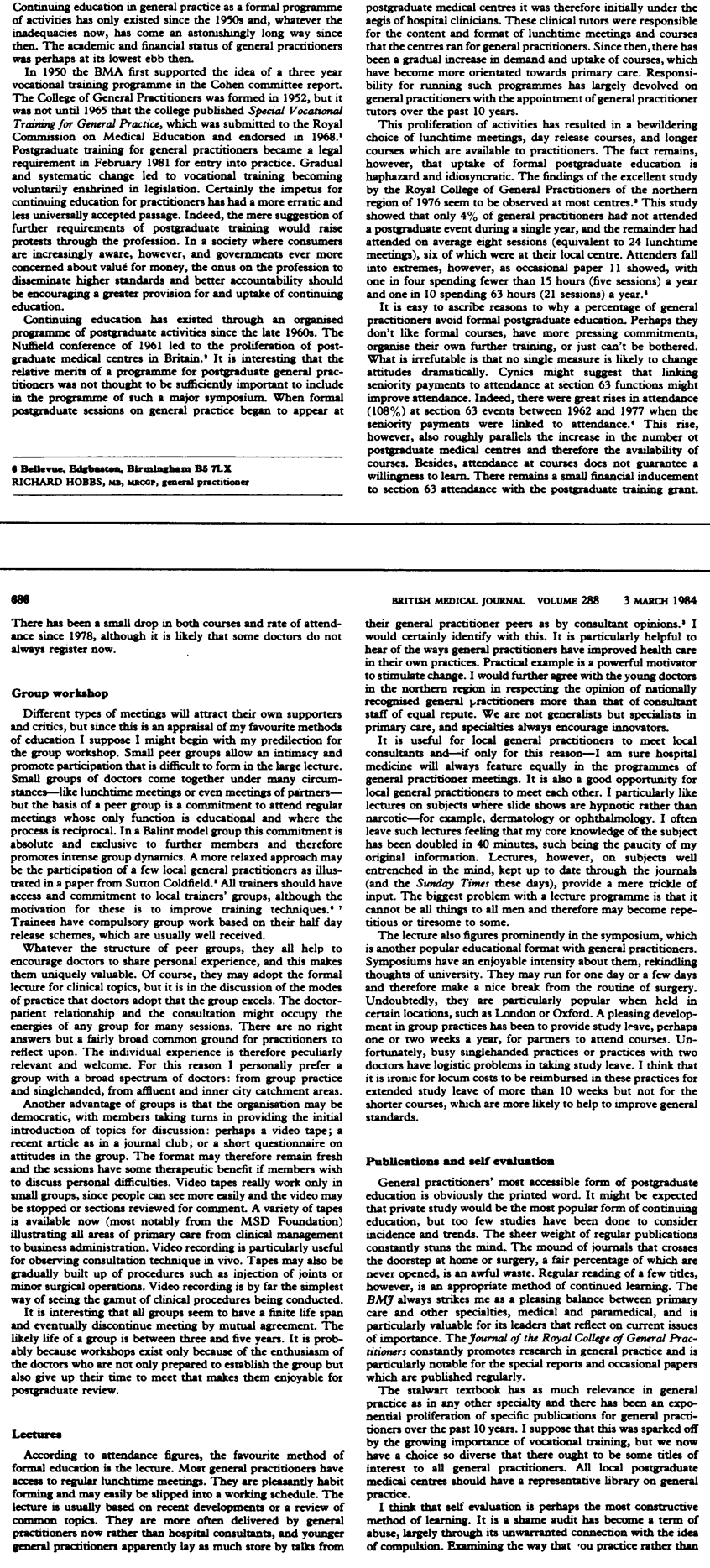

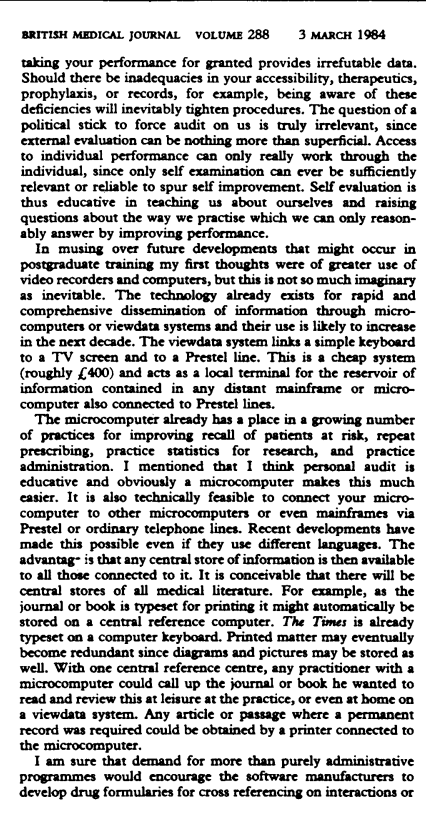

687

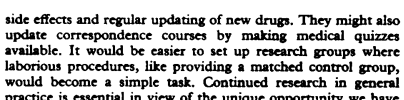
practice is essential in view of the unique opportunity we have
because of the structure of the Health Service to perform major providing education to us all. II hope that postreraduate medical centres will eventually
maintain selections of video tapes for lending alongside books. Particularty uasful are consultation technique and clinical
procedures, and as a highly portable form of tape-slide presenta-
tion they could be viewed at home or the centre. Many doctorn tion they could be viewed at home or the centre. Many doctors
have started receiving sponsored medical video programmes
from the popular weetly journals and these videos seem to have from the popular weechly journals and these videos seem to have I don't think that anything in the future could replace lectures, small groups, or symposiums, since they offer personal
contact with other practitioners as well as education. What would like to see is a more universal acceptance of their value,
with a a less polarised franchise of $10 \%$ high users and $25 \%$ virtual non-users." A thriving postgraduate education programme has existed in the United Sates since the 19605 .
Perhaps this will only come about in the United Kingdom if there is a reduction in practice worklood achieved with more

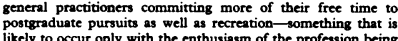
likely to occur only with the enthusiasm of the profession beeing
equally matched by financial encouragement from the govern-

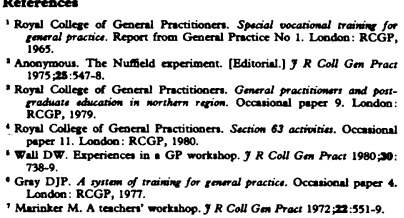

Diary of Urben Marke: 1880-1940

The complaints at Baldwin's went merrily on until at the end of
1912 I hed zeriout thoughts of retigning the appointment. I could

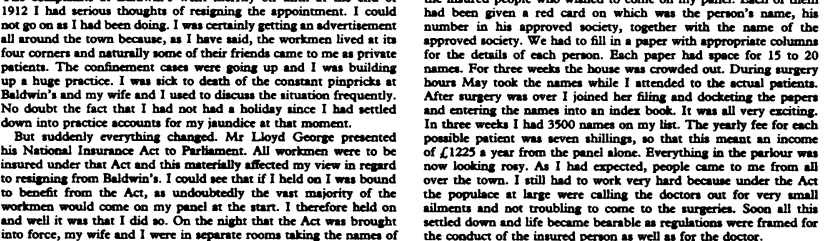

BRITISH MEDICAL JOURNAL VOLUME $288 \quad 3$ MARCH 1984

\section{Practice Research}

\section{Approval of trainers and training practices in the Oxford} region: evaluation

THEO P C SCHOFIELD, JOHN C HASLER

Abetract

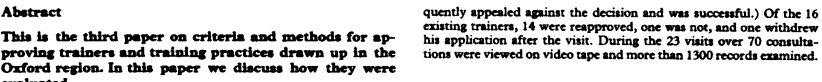
troduction

The criteria for the approval of trainers and training practices and the method of assestment that were proposed by a working
party in the Oxford refion have been described in two previous
papers (18 February, p 538 ; 25 February, p 612 ). When these general practice agreed chat there should be a six month period of

Methods

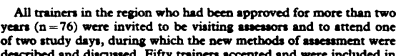

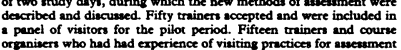

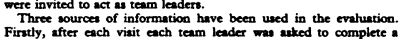

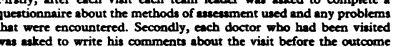

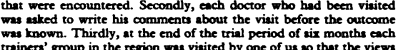

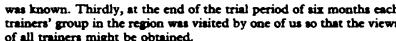
Revults

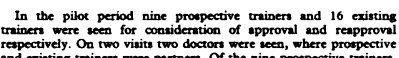

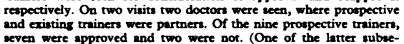

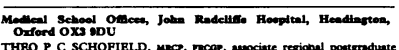

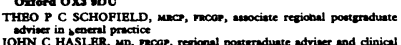
becturet in penereni practioes Criteris

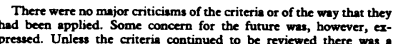

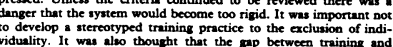

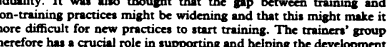

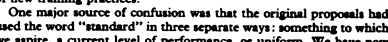

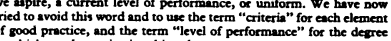

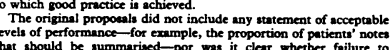

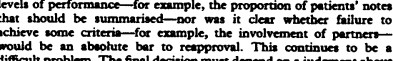

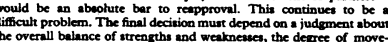

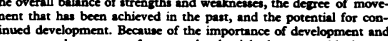

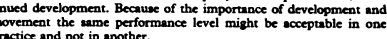

vite There was general support for continuing this method of ascestment
visits, thought reveral specific problems were rilied.

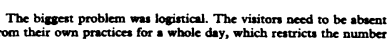

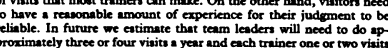

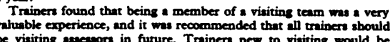

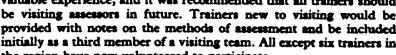
of new training prectices in supporting and belping the development 